\title{
Introduction to the HICSS-55 Software Development for Mobile Devices, the Internet-of-Things, and Cyber-Physical Systems Minitrack
}

\author{
Tim A. Majchrzak \\ University of Agder, \\ Kristiansand, Norway \\ timam@uia.no
}

\author{
Tor-Morten Grønli \\ Kristiania University College, \\ Dep. Technology, Oslo, Norway \\ tor-morten.gronli@kristiania.no
}

\author{
Hermann Kaindl \\ TU Wien, Inst. of Computer Tech., \\ Vienna, Austria \\ hermann.kaindl@tuwien.ac.at
}

Applications for mobile devices (apps) have facilitated the success of smartphones and tablets. By using apps, the multi-purpose hardware of modern devices can be utilized to the full extent. Despite much progress in development methods, software development kits, and frameworks, app development poses many challenges. This is even more so for novel mobile devices such as wearables and for the hardware that constitutes the Internet-of-Things (IoT) and Cyber-Physical Systems (CPS). Compatibility, performance, battery-saving, and security and safety are only some of the issues that are mainly driven by the quality of the used software. A satisfying level of this quality in many cases is very hard to achieve and proper techniques for testing and formal verification are needed.

Experiences and methods from classical software development can only be utilized to some degree. Moreover, the inherent challenges of the respective new devices ask for novel solutions. The challenges sketched above are reinforced by the conditions that development activities meet. Typical particularities include the need for multi-platform development, device fragmentation, context-sensitivity, low computational power, little memory, energy conservation requirements, and the heterogeneity of users. With the emergence of multi-platform and multi-device, the new golden standard are applications not only across software ecosystems, but across hardware platforms such as laptop, mobile, tablets, embedded devices, sensors and wearables. Therefore, new threads of research are needed to tackle these issues and to pave the way for improved software development, better business producibility and improved user experience (UX).

This minitrack started as Mobile App Development (HICSS-49 [1] and HICSS-50 [2]) before broadening to Software Development for Mobile Devices, Wearables, and the Internet-of-Things (HICSS-51 [3] and HICSS-52 [4]). Since its fifth year (HICSS-53 [5] and HICSS-54 [6]), we adapted it to the further changing landscape to keep it attractive to the community, now including cyber-physical systems (CPS).

HICSS-55 will be the second virtual HICSS. We will again organize a virtual session, since the one we did for HICSS-54 was well received and offered insights, good discussions, and fun!

The minitrack covers three papers:

1. Software Design of Energy-Aware Peripheral Control for Sustainable Internet-of-Things Devices by Michael Uelschen and Marco Schaarschmidt

2. One-click Application Deployment - An Approach for Automated Deployment of Instantiable Cross-platform Mobile Applications by Arnold Arz von Straussenburg and Friedrich Chasin

3. The Use of Cross-Platform Frameworks for Google Play Store Apps by Andreas Biørn-Hansen, Tor-Morten Grønli, Tim A. Majchrzak, Hermann Kaindl, and Gheorghita Ghinea

We are glad that we again had many helping hands. We are proud that all authors that submitted papers to our track got at least three - most even four - constructive reviews as well as an additional meta-review. We think that we outperform many journals with this effort in giving authors advice, whether their papers are accepted or not. And continuing this to the sixth edition of the minitrack makes us glad. Therefore, we would like to thank (and explicate!) our program committee for their continued arduous work:

- Sebastián Echeverría, Carnegie Mellon Software Engineering Institute

- Siri Fagernes, Kristiania University College

- Gheorghita Ghinea, Brunel University

- Adrian Holzer, University of Neuchâtel, Switzerland

- Shah Rukh Humayoun, San Francisco State University 
- Cristian Mateos, ISISTAN - UNICEN - CONICET

- Syed Atif Mehdi, University of Central Punjab

- Laura Po, University of Modena and Reggio Emilia

- Mohammad Tafiqur Rahman, University of South-Eastern Norway

- Rocco Raso, Universität des Saarlandes

- Sergio Ríos-Aguilar, Universidad Politecnica de Madrid

- Daniel Rodriguez,University of Alcalá

- Davide Rossi, University of Bologna

- Filippo Sanfilippo, University of Agder

- Tacha Serif, Yeditepe University

- Davor Svetinovic, Khalifa University

- Bastian Tenbergen, SUNY Oswego

- Tony Wasserman, Carnegie Mellon University Silicon Valley

- Oliver Werth, Leibniz Universität Hannover

- Alejandro Zunino, ISISTAN - UNICEN - CONICET

\section{References}

[1] T. A. Majchrzak and H. Heitkötter, "Introduction to the mobile app development minitrack," in Proceedings 49th Hawaii International Conference on Systems Science (HICSS-49), p. 5682, IEEE Computer Society, 2016.

[2] T. A. Majchrzak and T.-M. Grønli, "Introduction to the mobile app development minitrack," in Proceedings 50th Hawaii International Conference on Systems Science (HICSS-50), p. 6161, AIS Electronic Library (AISeL), 2017.

[3] T. A. Majchrzak and T.-M. Grønli, "Introduction to the HICSS-51 software development for mobile devices, wearables, and the internet-of-things minitrack," in Proceedings 51th Hawaii International Conference on Systems Science (HICSS-51), p. 5686, AIS Electronic Library (AISeL), 2018.

[4] T. A. Majchrzak and T.-M. Grønli, "Introduction to the HICSS-52 software development for mobile devices, wearables, and the internet-of-things minitrack," in Proceedings 52th Hawaii International Conference on Systems Science (HICSS-51), pp. 7399-7400, AIS Electronic Library (AISeL), 2019.

[5] T. A. Majchrzak, T.-M. Grønli, and H. Kaindl, "Introduction to the HICSS-53 software development for mobile devices, the internet-of-things, and cyber-physical systems minitrack," in Proceedings 53th Hawaii International Conference on Systems Science (HICSS-53), pp. 6629-6630, AIS Electronic Library (AISeL), 2020.

[6] T. A. Majchrzak, T.-M. Grønli, and H. Kaindl, "Introduction to the HICSS-53 software development for mobile devices, the internet-of-things, and cyber-physical systems minitrack," in Proceedings 54th Hawaii International Conference on Systems Science (HICSS-54), AIS Electronic Library (AISeL), 2021. 